\title{
Formation and evolution of a bicontinuous structure of PMMA membrane during wet immersion process
}

\author{
Chun-Yin Kuo a, Shiun-Lian Su ${ }^{a}$, Hui-An Tsai ${ }^{\mathrm{a}, \mathrm{b}, *}$, Yu-Shen Su${ }^{\mathrm{c}}$, Da-Ming Wang a,c , Juin-Yih Lai ${ }^{\mathrm{a}}$ \\ a RED Center for Membrane Technology, Chung Yuan University, Chung-Li 320, Taiwan \\ ${ }^{\mathrm{b}}$ Department of Material and Fiber, Nanya Institute of Technology, Chung-Li 320, Taiwan \\ ${ }^{c}$ Department of Chemical Engineering, National Taiwan University, Taipei, Taiwan
}

\section{A R T I C L E I N F O}

\section{Article history:}

Received 2 October 2007

Received in revised form 13 February 2008

Accepted 16 February 2008

Available online 10 March 2008

\section{Keywords:}

Bicontinuous structure

PMMA

FTIR-microscopy

Wet immersion

Spinodal decomposition

\begin{abstract}
A B S T R A C T
In this study, a bicontinuous structure of poly(methyl methacrylate) (PMMA) membrane was obtained via wet immersion method by coagulating PMMA/1,4-dioxane casting film into alcohol bath. Freeze-dried method was utilized to investigate the evolution of membrane structure at various coagulation times. The FTIR-microscope, scanning electronic microscope (SEM), ternary phase diagram as well as light transmission were used to investigate the formation and structure evolution mechanism of PMMA membrane. The results show that the bicontinuous structure can be formed on the top surface of PMMA membrane as contacted the PMMA/1,4-dioxane casting film with $n$-propanol only 2 s. Furthermore, it also can be found that as increasing the immersion time in $n$-propanol bath over than $1.5 \mathrm{~min}$, the bicontinuous structure would be broken up to form nodules morphology due to capillarity effect, or led to a matrix/disperse domain morphology by coalescence effect. The analysis of FTIR-microscopy shows that the PMMA polymer concentration in the top layer of nascent membrane was decreased as immersed the casting film into $n$-propanol bath. The lower PMMA polymer concentration in the top layer could cause the composition path entered into the unstable region, resulting in the formation of bicontinuous structures.
\end{abstract}

(c) 2008 Elsevier B.V. All rights reserved.

\section{Introduction}

The phase inversion method is the most widely used technique for membrane preparation [1,2]. The membrane morphology can be controlled depending on the casting condition [3-6], polymer solution [7-9] and the composition of coagulation bath [6,10-14]. For understanding and controlling the membrane structure, two factors, thermodynamics and kinetics must be clarified. The thermodynamics, equilibrium phase diagram, can show the stable region of casting solution and the type of phase separation such as spinodal decomposition (SD) and nucleation and growth (NG).

Two kinds of kinetics play an important role in membrane formation, one is phase separation rate and the other one is the change of polymer solution composition due to that exchange of solvent and non-solvent. The phase separation rate during the formation of porous membrane can be studied by light scattering method [15]. Many mass transfer models have been developed to calculate the composition change during membrane formation [16-19]. Fig. 1 shows the schematically ternary-phase diagram which can indicate that the composition path at the top of the casting film

\footnotetext{
* Corresponding author at: Department of Material and Fiber, Nanya Institute of Technology, Chung-Li 320, Taiwan. Tel.: +886 3 4361070x4101.

E-mail address: huian@nanya.edu.tw (H.-A. Tsai).
}

may follow three routes during the immersion precipitation process. For casting solution with higher polymer concentration and a higher ratio of the outflow of the solvent compared to the inflow of the nonsolvent, the composition of the top part of the casting solution may follow the first route up to the vitrification region and consequently, an asymmetric membrane with a dense top layer can be formed. For another case where the ratio of the outflow of the solvent to the inflow of the nonsolvent is relatively low, the composition of the casting solution at the top layer can follow the second path toward binodal and immediately the top layer of the casting solution demix resulted in the formation of small porous membrane. The third composition path follows the decrease of the polymer concentration on the top layer and thus, the phase separation occurs near the critical point, resulting in the formation of bicontinuous structure.

By using harsh nonsolvent such as water as the coagulant, finger-like membrane morphology with a dense skin layer can be obtained usually due to instantaneous demixing. However, as weak non-solvent such as alcohol or solvent/non-solvent mixture was used as the coagulant, porous surface membrane usually can be fabricated [20-23]. Cheng et al. [24] have reported that the polymer concentration of the top layer of PVDF membrane was lowered due to the exchange rate of solvent and non-solvent was decreased, resulted in a porous structure of the top layer. While very few studies have been reported on the change of composition 


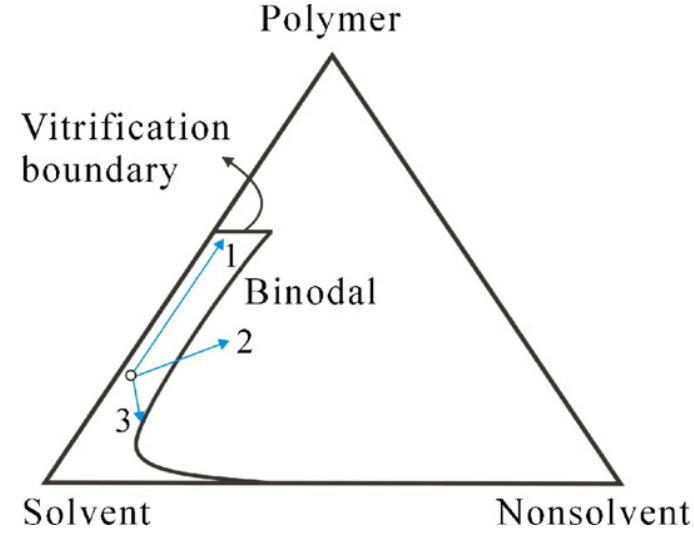

Fig. 1. The composition path schematically diagram of the top of casting film during the immersion precipitation process.

during the porous membrane formation process by experiments method.

Matsuyama and Zoppi $[15,25]$ have used light scattering method to indicate that phase separation could be occurred by spinodal decomposition when weak non-solvent was used as the coagulant during the immersion precipitation process. However, a bicontinuous structure was not remarkably observed in the final morphology of membrane.

Thus, for using weak non-solvent as coagulant system, the phase separation mechanism and it related to the finial morphology of membrane was still no consistent viewpoint. Hence, in this work, the composition change of polymer/solvent/non-solvent at different depth beneath the surface of casting film and as function of time were analyzed by using FTIR-microscopy. The freeze-dried method was used to fix membrane morphology rapidly to identify the evolution of membrane structure at the early stage and latter stage of phase separation process. This fundamental study is believed to be important for application to membrane preparation.

\section{Experimental}

\subsection{Materials}

The polymer, poly(methyl methacrylate) (PMMA), used in this study was supplied by Aldrich Co. Ltd. The number average molecular weight $(\overline{M n})$ is $1.2 \times 10^{5} \mathrm{~g} / \mathrm{mol}$. 1,4-Dioxane (Showa Co. Ltd.) was used as the solvent. $n$-propanol of reagent grade and water were used as coagulants in this study.

\subsection{Membrane preparation}

PMMA was dissolved in solvent, 1,4-dioxane, to form $20 \mathrm{wt} . \%$ of casting solution and was then stored at $30^{\circ} \mathrm{C}$ to degas at least 1 day. The degassed casting solution was cast on a glass plate to a thickness of $300 \mu \mathrm{m}$ with Gardner knife at $30^{\circ} \mathrm{C}$. The cast film was immediately immersed in $30^{\circ} \mathrm{C}$ of $n$-propanol bath. The cast film was kept in the $n$-propanol bath to exchange the solvent and coagulant for different periods and then was transferred to liquid nitrogen to fix the membrane structure quickly. After that, the liquid nitrogen frozen membrane was freeze-dried to remove the residual solvent and non-solvent.

\subsection{Phase diagram}

Cloud-point curves of the PMMA/1,4-dioxane/n-propanol ternary system were obtained at $30^{\circ} \mathrm{C}$ by using a simple titration method.

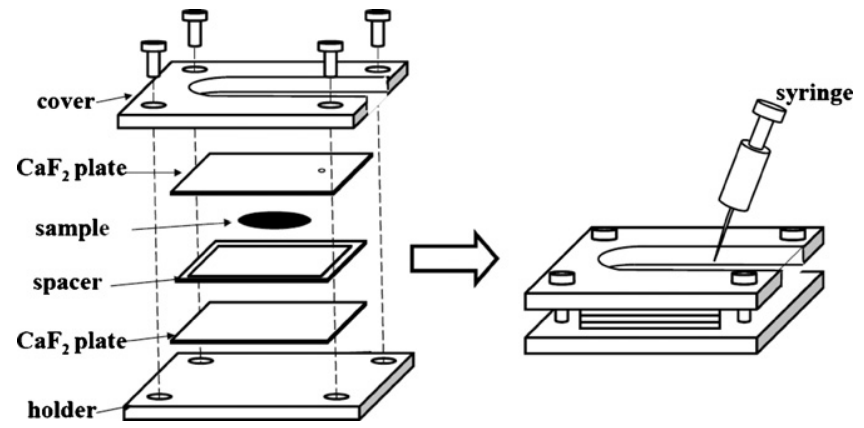

Fig. 2. Schematic representations of sample apparatus for FTIR-microscope experiment.

\subsection{SEM observation}

The morphology of the surface and the cross-section of the membrane were observed with the scanning electron microscope (SEM, Hitachi, Model: S-3000N). The samples were immersed in liquid nitrogen to fracture and then were sputtered with Au.

\subsection{Light transmission}

Light transmission experiment was performed to measure the time of the onset of liquid-liquid demixing in the casting solution. To carry out the light transmission experiment, a lamp was placed above the coagulation bath as light source and a light detector beneath the coagulation bath was used to measure the light transmittance.

\subsection{FTIR-microscope observation}

A FTIR-microscope (PerkinElmer LE186-0078) equipped with a liquid cell was used for detecting the weight fraction of composition at different spots during membrane formation. PMMA/1,4-dioxane polymer solution was contained in the liquid cell composed of two $\mathrm{CaF}_{2}$ plates and a Teflon spacer with $15 \mu \mathrm{m}$ thickness. The liquid cell holder (Fig. 2) was placed horizontally on the sample stage of the FTIR-microscope and then the gap supported by spacer between the plates enabled the injection of the non-solvent by a syringe. By adjusting the positions of the sample stage, the interface between the air and solution was judged by the optical image and the infrared spectra at desired spots in the solutions were obtained. An aperture with $20 \mu \mathrm{m}$ in width and $300 \mu \mathrm{m}$ in length was used to confine the IR transmission area for collecting the localized spectra. The wave number of 3340-3500, 1732 , and $1123-1127 \mathrm{~cm}^{-1}$ were used to characterize the concentration of $n$-propanol, PMMA, and 1,4-dioxane, respectively. Among the concerned ternary species, the calibration curves of PMMA/1,4dioxane were established firstly. The ratio of binary characteristic peak heights were determined and converted to that of binary mass fraction and accordingly the relative amount of PMMA/1,4-dioxane and $n$-propanol/1,4-dioxane would be acquired. In this study, the sum of total weight fraction for the binary or ternary components was one and the local average compositions were calculated at different positions and time.

\section{Results and discussion}

\subsection{Evolution of the morphology of PMMA membrane in n-propanol}

Polymer casting film tended to become less transparent or nontransparent during the formation of polymeric membrane resulted 


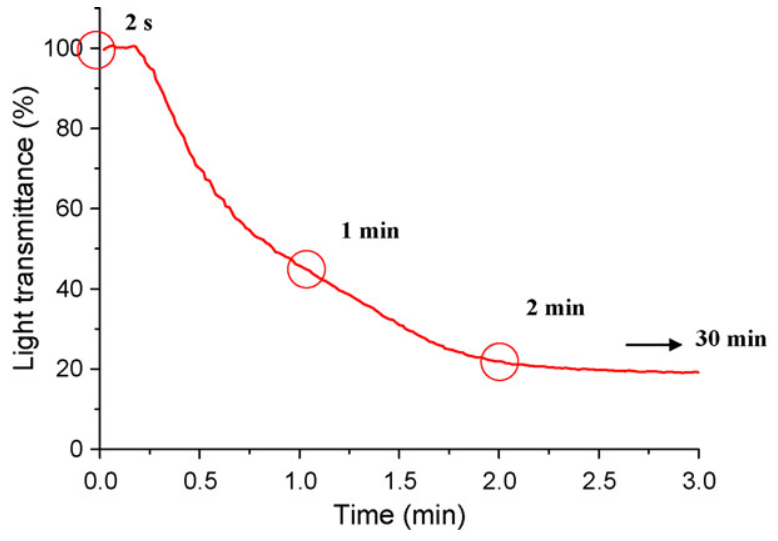

Fig. 3. The light transmission of PMMA casting film which was immersed in $n$ propanol bath.

from the phase separation as immersed the casting film into coagulation bath. The light transmittance of casting film began to decrease onset of phase separation of polymer solution, and the light transmission data could provide information with respect to phase separation and gel formation. Fig. 3 shows the light transmittance of PMMA/1,4-dioxane casting film which was immersed into the $n$-propanol bath. It can be found that the PMMA/1,4-dioxane $/ n$ - propanol system represented the classic delay demixing system as shown in Fig. 3.

During the phase separation process, the nascent morphology of membrane could be evolved to different type before it was solidified. Herein, in order to observe the evolution of the morphology of the PMMA membrane before it was solidified, liquid nitrogen was utilized to fix the structure forming in coagulant rapidly and then the solvent and non-solvent were removed in vacuum, so called freeze-dried method. According to the light transmission curve as shown in Fig. 3, the PMMA cast film was immersed into $n$-propanol bath for various periods (ex. $2 \mathrm{~s}, 1,2$ and $30 \mathrm{~min}$ ) to prepare the membranes. The cross-section and surface images of the PMMA membranes were shown in Figs. 4 and 5, respectively. The data in Figs. 4 and 5 depict that a bicontinuous top-surface structure can be formed as contacted the PMMA casting film with $n$-propanol only $2 \mathrm{~s}$. However, at this moment, the light transmittance was still kept almost $100 \%$ as can be seen in Fig. 3. As increasing the immersion time to 1 or $1.5 \mathrm{~min}$, the porous structure region of the cross-section was broad and remarkable as shown in Fig. 4(B) and (C). Nevertheless, the uniform porous structures were translated to nodules structure near the top-surface of membrane and the cellular structures have formed below as increasing the immersion time to $2 \mathrm{~min}$ (Fig. 4(D)). Moreover, the size of nodules and cellular structure was increased as prolonged the immersion time to $30 \mathrm{~min}$.

The evolution of the morphology also can be confirmed with surface structures as shown in Fig. 5. From the magnification of
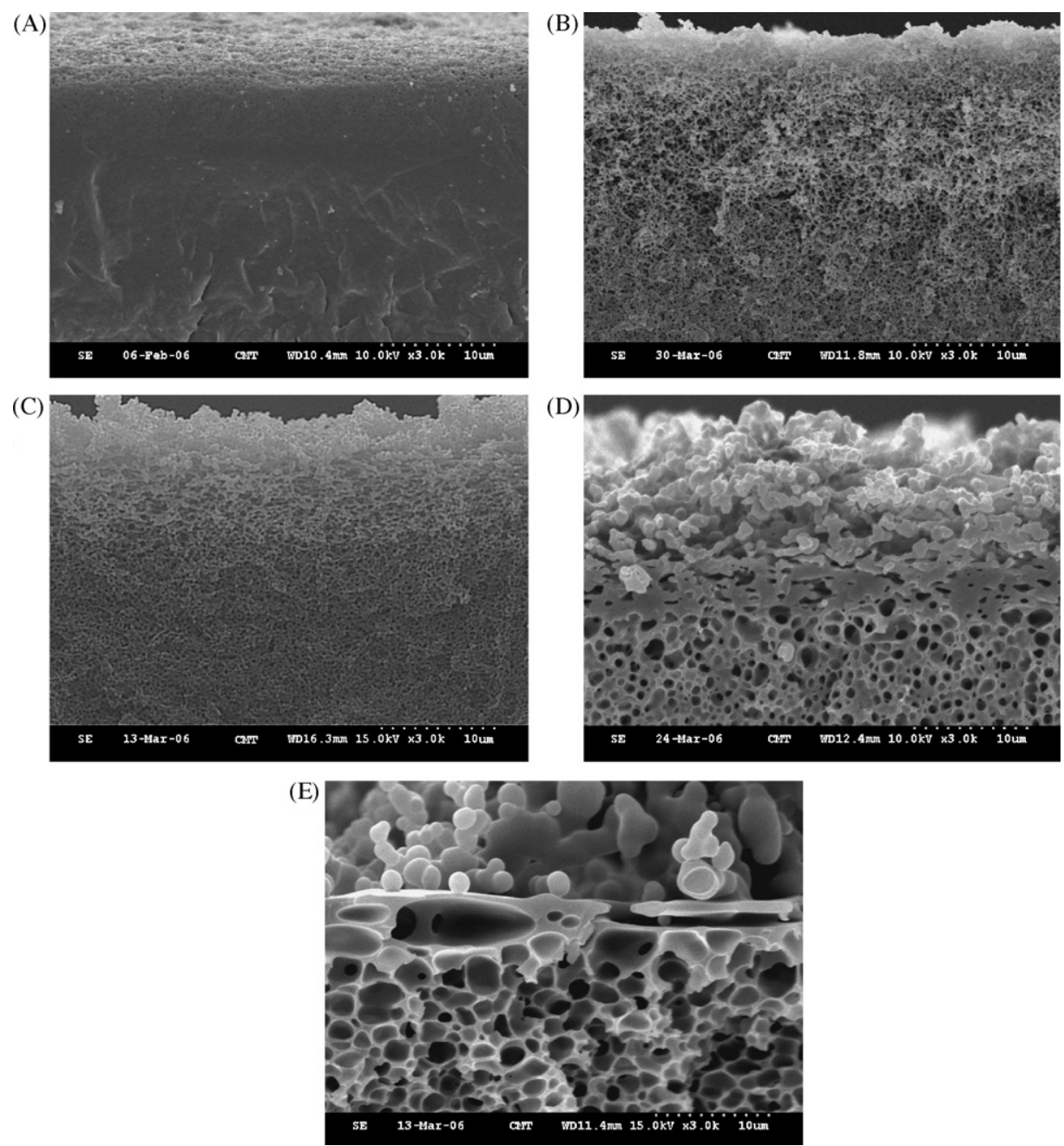

Fig. 4. The cross-sectional morphology of PMMA membranes which were immersed in $n$-propanol bath for (A) $2 \mathrm{~s}$, (B) $1 \mathrm{~min}$, (C) $1.5 \mathrm{~min}$, (D) $2 \mathrm{~min}$ and (E) $30 \mathrm{~min}$ ( $3 \mathrm{k} \times$ ). 


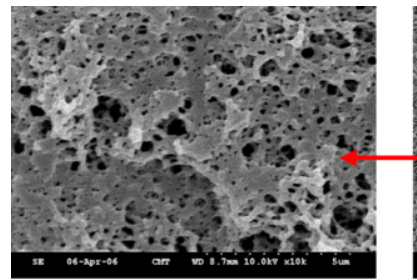

(A)

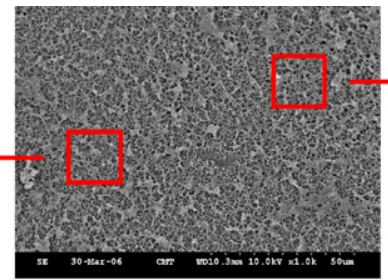

(B)

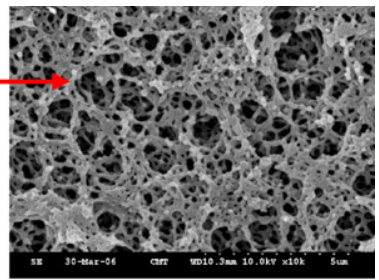

(C)

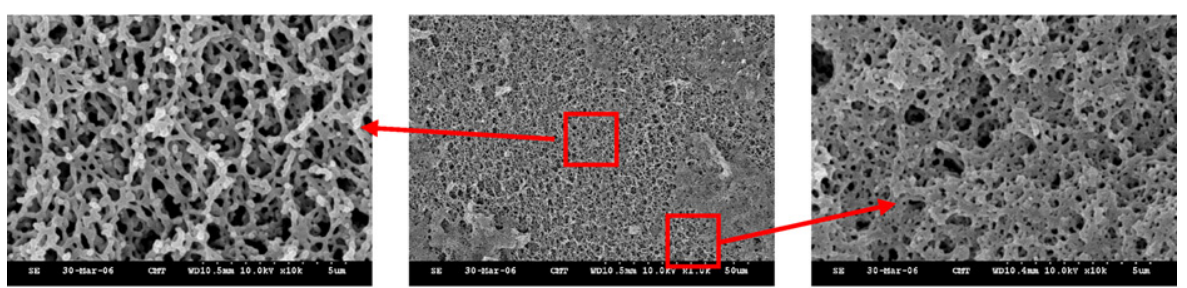

(D)

(E)

(F)

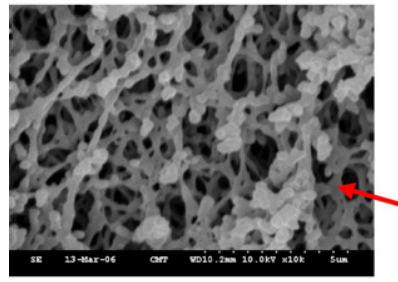

(G)

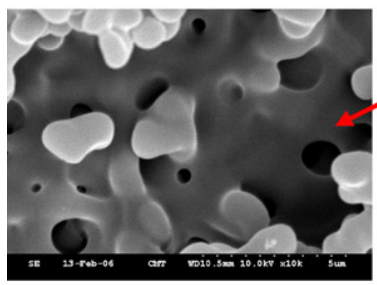

(J)

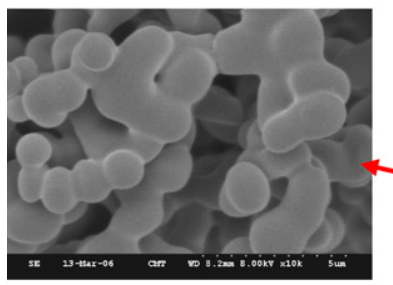

(M)

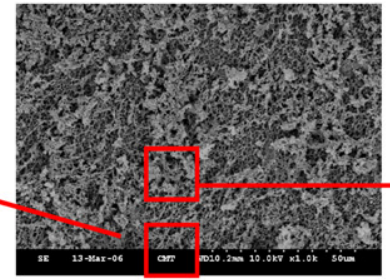

(H)

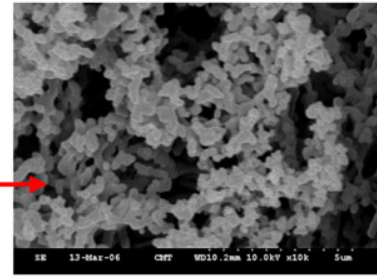

(I)

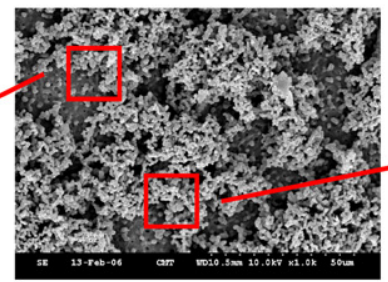

(K)

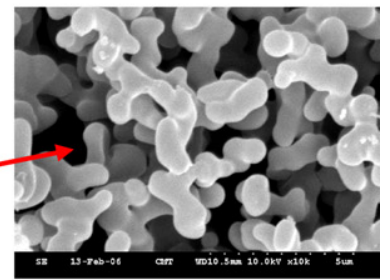

(L)

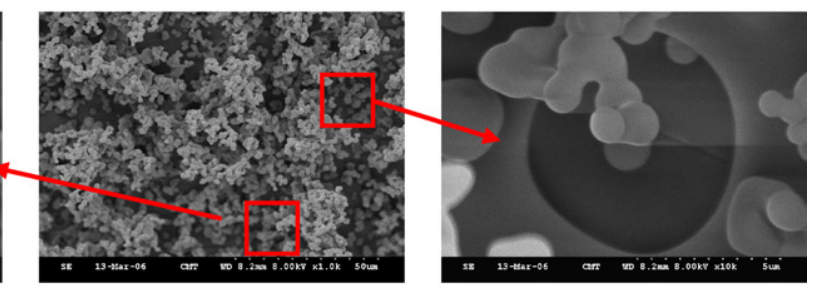

(O)

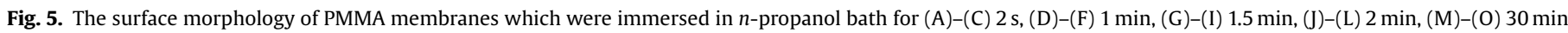
(magnification: (B), (E), (H), (K), (N) $1 \mathrm{k} \times$; the other: $10 \mathrm{k} \times$ ).

surface images, it can be found that the bicontinuous structure has been formed as contacted PMMA/1,4-dioxane casting film with $n$-propanol only $2 \mathrm{~s}$ (Fig. 5(C)), even though some of indistinct bicontinuous structures were existed as shown in Fig. 5(A). As kept on immersing the casting film in $n$-propanol bath for $1 \mathrm{~min}$, the surface morphology has been evolved slightly, but it was not obvious (Fig. 5(D)-(F)). When the immersion time was prolonged more than $1.5 \mathrm{~min}$, the bicontinuous structure has been translated to different type of morphology as can been seen in Fig. 5(G)-(O). In some region, the bicontinuous structure has been evolved to nodule type structure as shown in Fig. 5(I). However, the bicontinuous structure also could be maintained visibly in other region. Furthermore, when the immersion time kept increasing, the bicontinuous structure was disappeared and translated to nodules or matrix/disperse domain morphology. The size of the nodules on the top-layer of membrane was increased as increasing the immersion time as shown in Fig. 5(L) and (O). Moreover, the smaller close pores in the matrix/disperse domain morphology of the sub-layer tended to form bigger close pores. Combined with the surface and cross-section images, it was believed that the bicontinuous structure can be formed in the early state of contacting with $n$-propanol. However, this bicontinuous structure would be evolved further as increasing the immersion time in $n$-propanol bath. That is, in the late stage, the porous lacy-like structure would be broken up to nodules structure, or led to a matrix/disperse domain morphology by coalescence effect. Moreover, the evolutions of the morphologies of the PMMA membranes by using other alcohols (methanol, ethanol, and $n$-butanol) as the coagulant have also the same result.

\subsection{The composition of polymer solution analysis during membrane formation}

Eckelt et al. [26] have investigated the formation mechanism of micro- and nano-spheric particles in cellulose acetate membrane 

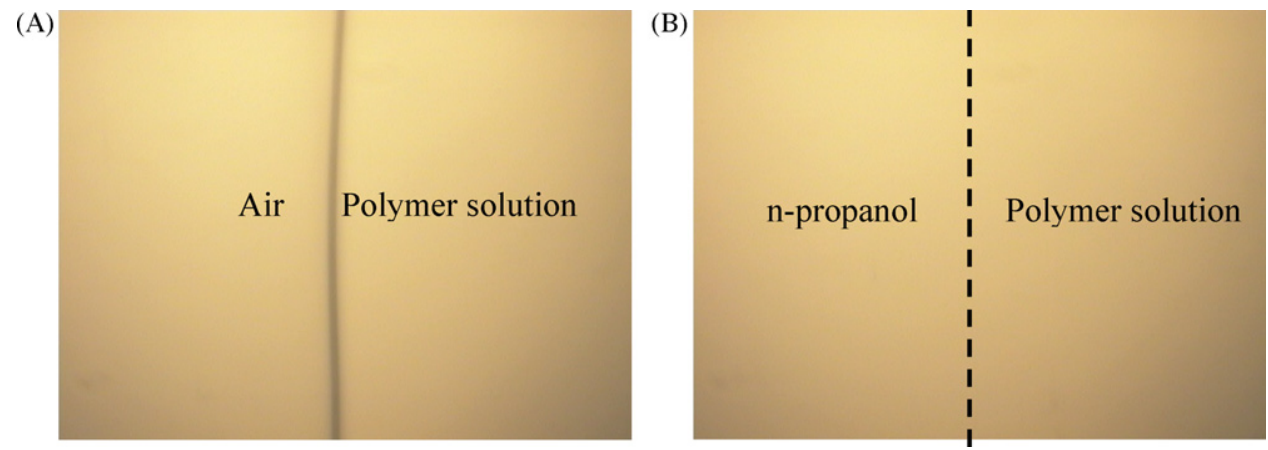

Fig. 6. The FTIR-microscopy observation of PMMA/1,4-dioxane solution. (A) No contacted with $n$-propanol and (B) contacted with $n$-propanol for 2 min (150×).

by using $n$-propanol as the coagulant. It was found that the polymer beads on the surface of the membrane were resulted from the polymer poor-phase transporting from the bulk phase during phase separation process. However, in this study, it can be found that the nodule particle was evolved from the bicontinuous structure as can be seen from the SEM observation of the surface and cross-section morphology of membrane (Figs. 4 and 5). Obviously, the above statement about the formation mechanism of nodules might be not corresponded to the experimental results of the PMMA system.

In order to interpret the mechanism of the nodule particle, FTIR-microscope was used to analyze the composition change at different depth beneath the surface of the PMMA polymer solution as contacted with $n$-propanol for various time. Fig. 6(A) shows the FTIR-microscopy image of PMMA polymer solution which was formed by dropping the PMMA polymer solution into the liquid cell. As can be seen in Fig. 6(A), a clear interface between polymer solution and air phase was formed because of the different refractive index between air phase and polymer solution. When $n$-propanol was injected into the liquid cell and contacted with polymer solution, the interface between polymer solution and air phase was disappeared as shown in Fig. 6(B) and the dot line was marked the original position of the interface between polymer solution and air phase. It meant that the difference of refractive index between polymer solution and air could be decreased by contacting with $n$-propanol.

Fig. 7 depicts the time dependence individual composition of PMMA/1,4-dioxane/n-propanol ternary system at $40 \mu \mathrm{m}$ depth beneath the surface of PMMA/1,4-dioxane polymer solution. It can

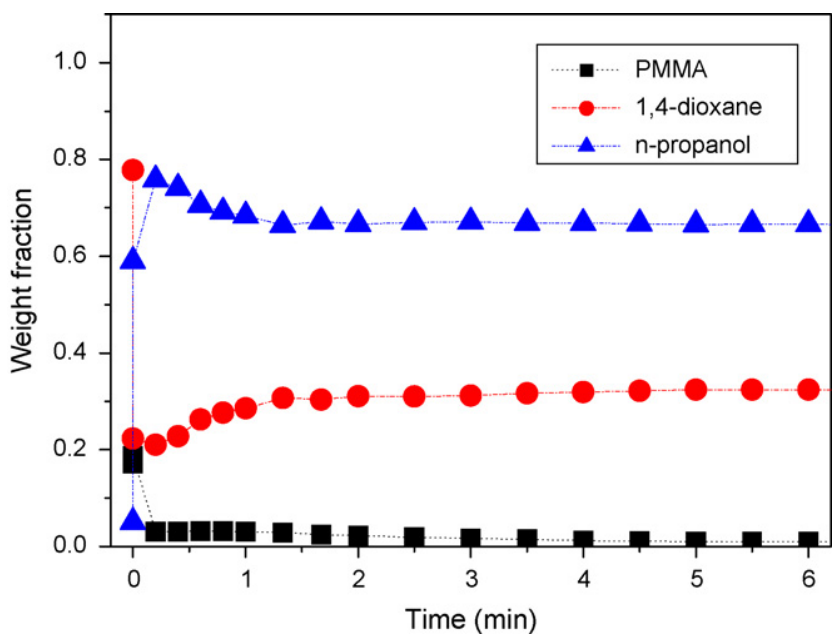

Fig. 7. The weight fraction of individual composition of PMMA/1,4-dioxane/npropanol at $40 \mu \mathrm{m}$ depth beneath the surface of PMMA/1,4-dioxane polymer solution which were analyzed by FTIR-microscopy. ( $\mathbf{\square})$ PMMA, ( $\mathbf{A}$ ) 1,4-dioxane and $(1$ ) $n$-propanol. be found that after contacted the PMMA/1,4 dioxane polymer solution with $n$-propanol, the weight fraction of PMMA polymer was lower than $n$-propanol one. In the beginning, the weight fraction of PMMA, 1,4-dioxane, and n-propanol were $0.2,0.8$ and 0 , respectively. After contacted PMMA/1,4-dioxane polymer solution with $n$-propanol for $10 \mathrm{~s}$, the weight fraction of PMMA decreased rapidly from 0.2 to 0.02 while $n$-propanol increased rapidly from 0 to over 0.6 at the same period. The composition change also can be used to explain why the difference of refractive index between polymer solution and air phase was decreased. When the depth beneath the surface of PMMA/1,4-dioxane polymer solution increased, the composition change was moderate. Figs. 8 and 9 reveal the data measured at 200 and $800 \mu \mathrm{m}$ depth beneath the surface of PMMA/1,4-dioxane polymer solution, respectively. For the case of $200 \mu \mathrm{m}$ depth beneath the surface of PMMA/1,4-dioxane polymer solution (Fig. 8), when the PMMA/1,4-dioxane polymer solution was contacted with $n$-propanol, the weight fraction of PMMA polymer was not so rapidly decreased as $40 \mu \mathrm{m}$ one, it was close to the initial composition ( $\sim 0.2)$ in $1 \mathrm{~min}$. As the contact time was increased longer than $1 \mathrm{~min}$, the weight fractions of PMMA and 1,4-dioxane decreased while $n$-propanol increased. For the $800 \mu \mathrm{m}$ depth beneath the surface of PMMA/1,4-dioxane polymer solution case (Fig. 9), the weight fraction of PMMA polymer was almost kept constant during the measurement process.

From the above results, it can be proved that the polymer concentration near the top layer of casting film could be rapidly reduced by using $n$-propanol as the coagulant. The composition change of ternary PMMA/1,4-dioxane/n-propanol system at early

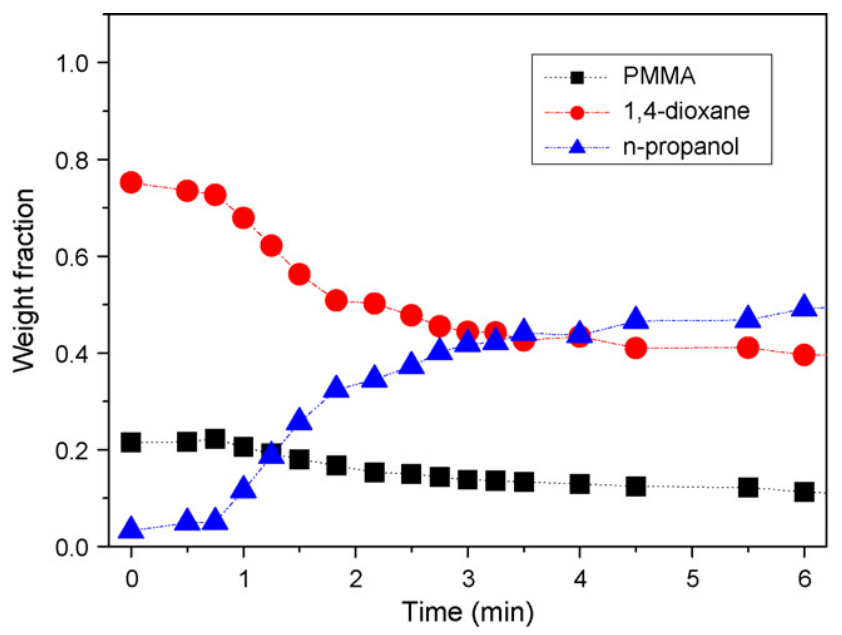

Fig. 8. The weight fraction of individual composition of PMMA/1,4-dioxane/npropanol at $200 \mu \mathrm{m}$ depth beneath the surface of PMMA/1,4-dioxane polymer solution which were analyzed by FTIR-microscopy. ( $\boldsymbol{\square})$ PMMA, ( $\mathbf{A}$ ) 1,4-dioxane and $(1)$-propanol. 


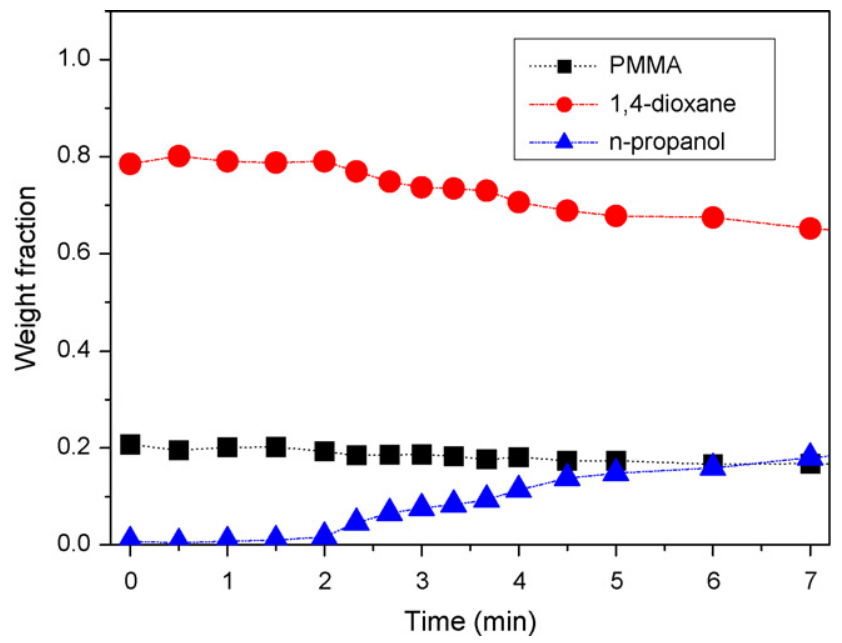

Fig. 9. The weight fraction of individual composition of PMMA/1,4-dioxane $/ n$ propanol at $800 \mu \mathrm{m}$ depth beneath the surface of PMMA/1,4-dioxane polymer solution which were analyzed by FTIR-microscopy. () PMMA, ( $\mathbf{\Delta}$ ) 1,4-dioxane and $(0$-propanol.

stage was valuable information to understand the membrane formation mechanism. Fig. 10 shows the change of the individual composition at different depth beneath the surface of PMMA/1,4dioxane polymer solution after contacted the PMMA/1,4-dioxane polymer solution with $n$-propanol for $30 \mathrm{~s}$. The data in Fig. 10 distinctly depict that at the $40 \mu \mathrm{m}$ position (near interface), the PMMA polymer weight fraction was very low while $n$-propanol one was very high. When the depth increased to 200 or $800 \mu \mathrm{m}$, the polymer weight fraction was almost the same as the original fraction while the $n$-propanol weight fraction was lower.

Following, the composition data at different depth with time analyzed from FTIR-microscopy were marked on the phase diagram as shown in Fig. 11. From the cloud-point curve of Fig. 11 (the ( $\Delta)$ point), it can be found that for the PMMA/1,4-dioxane/n-propanol system, the polymer solution was needed to add over $50 \mathrm{wt} . \%$ of $n$ propanol to induce phase separation, it meant that the $n$-propanol was one of the weak non-solvent for the PMMA/1,4-dioxane system. At the $200 \mu \mathrm{m}$ depth beneath the surface of PMMA/1,4-dioxane polymer solution, the composition path went toward lower polymer concentration and entered into phase separation region after

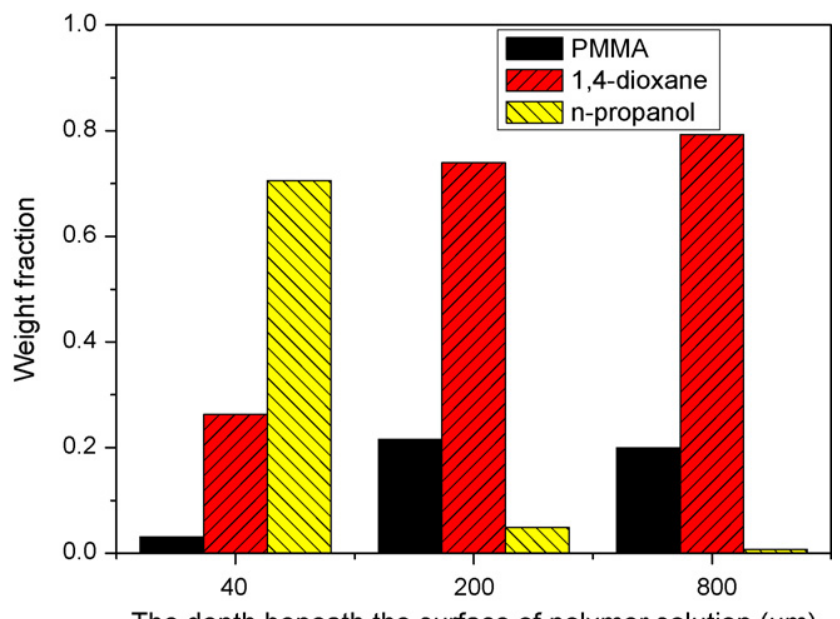

Fig. 10. The weight fraction of individual composition of PMMA/1,4-dioxane/npropanol at different depth beneath the surface of PMMA/1,4-dioxane polymer solution after contacting with $n$-propanol for 30 s. (⿴) PMMA, (《) 1,4-dioaxane and (N) n-propanol.

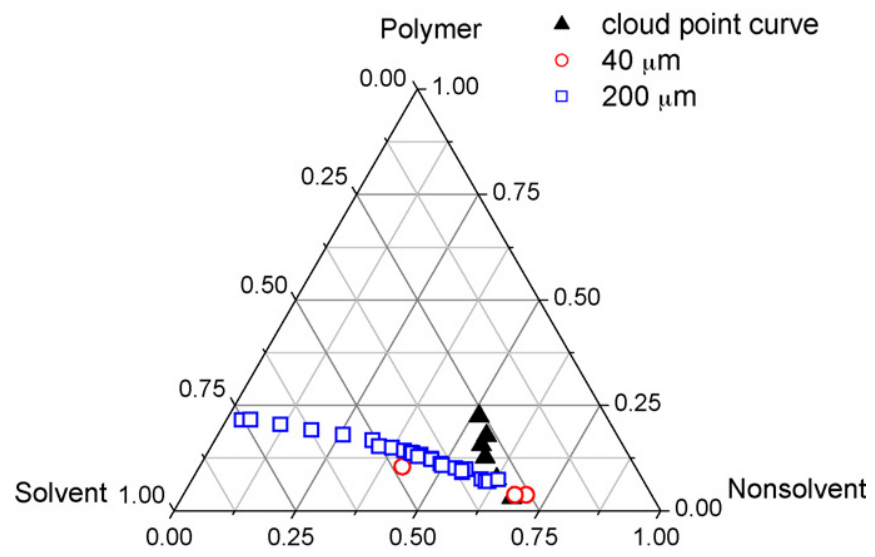

Fig. 11. The time dependence composition paths of PMMA casting film at different position after contacting with $n$-propanol. Depth beneath the surface $(\bigcirc) 40 \mu \mathrm{m}$, ( $\square$ ) $200 \mu \mathrm{m}$ and $(\boldsymbol{\Delta})$ the cloud-point curve of PMMA/1,4-dioxane/n-propanol at $30^{\circ} \mathrm{C}$.

contacting with $n$-propanol for 20 min (the ( $\square$ ) point in Fig. 11). However, at the $40 \mu \mathrm{m}$ depth beneath the surface of PMMA/1,4dioxane polymer solution, the composition path rapidly went toward much lower polymer concentration (the $(\bigcirc)$ point in Fig. 11) and entered into phase separation region after contacting with $n$ propanol for few second. The phase separation path differed at different position of the casting film, provided useful interpretation for the phase separation mechanism by spinodal decomposition or nucleation and growth at different positions would be not the same.

Thus, according to the FTIR-microscopy and SEM results, it can be proved that the bicontinuous structure made of contacting with $n$-propanol was due to the rapidly decreased of polymer concentration in the surface of casting film. In other word, as the polymer concentration was properly low, the phase separation could be occurred at the region close to the critical point and entered into the unstable region (spinodal decomposition), resulting in the formation of bicontinuous structure. Besides, it was also found that as the contacted time of $n$-propanol increased over than $1.5 \mathrm{~min}$, the bicontinuous structure would be translated to nodule particle and matrix/disperse domain morphology. The possible mechanism was discussed as bellow.

\subsection{Evolution of bicontinuous structure at latter stage}

It was widely accepted that phase separation occurs at the region inside spinodal curve can cause the formation of bicontinuous membrane structure $[2,27,28]$. The subject of spinodal decomposition is very complex. This phenomenon has attracted the interest of physicist and polymer engineers. Much of the researches has been done with inorganic glasses, metal alloys or polymers [29-31]. Cahn [29] has developed a description of the kinetics of the early period spinodal decomposition by using a phenomenological diffusion model. The droplet coalescence phenomenon was treated theoretically by Siggia [30] for the intermediate-period spinodal decomposition. Tsai and Torkelson [27,32] have studied the phase separation mechanism and coarsening of PMMA membranes by using thermal induced phase separation (TIPS) method. During the very early stage of phase separation by spinodal decomposition, a membrane with lacy structure was formed. The effect of ripening or coalescence has been demonstrated to a significant in determining the final membrane morphology for phase separation by both spinodal decomposition and nucleation and growth [32]. It was widely accepted that the bicontinuous structure formed by spinodal decomposition could be changed to various morphologies by coarsening effect. 


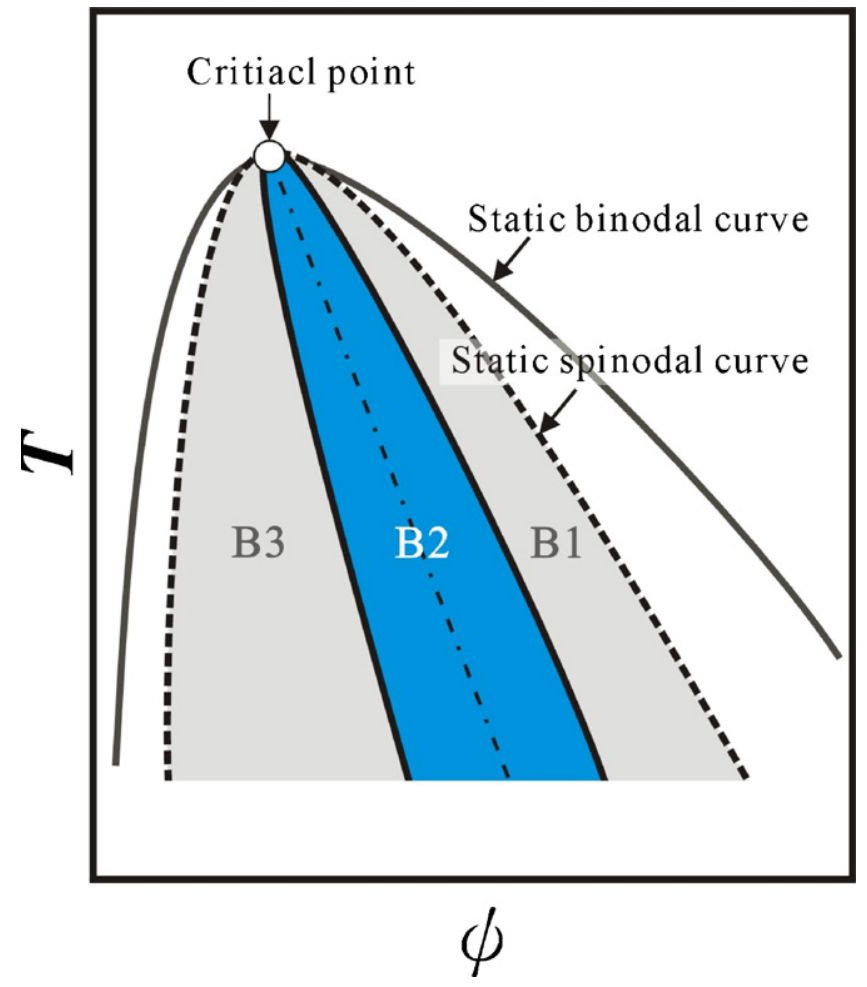

Fig. 12. A typical phase diagram of fluid mixtures: polymer solutions as an example. Depending upon the composition symmetry, various types of phase separation are observed [28].

Tanaka [28] has summarized the view of phase separation, taking polymer solutions as shown in Fig. 12. The phase separation kinetics has been classified into three types without any exception: bicontinuous and droplet spinodal decomposition in the unstable region and nucleation and growth type phase separation in the metastable region. He has considered bicontinuous phase separation of a symmetric compositions $\left(\Phi_{\mathrm{A}} \sim 1 / 2 ; \Phi_{\mathrm{A}}\right.$ : the volume fraction of the A rich phase) and droplet phase separation of an offsymmetric compositions $\left(\Phi_{\mathrm{A}} \neq \sim 1 / 2\right)$ separately. Thus, the spinodal region could be divided into bicontinuous pattern (the B2 region in Fig. 12) and droplet pattern (the B1 and B3 regions in Fig. 12, which were representation of solvent rich droplet (B1) and polymer rich droplet (B3)). Tanaka has also revealed that the most important concept of the pattern-evolution processes for bicontinuous and droplet spinodal decomposition is the self-similar growth of domains, which ensures the existence of only one length scale.

As described above, the bicontinuous structure occurred by spinodal decomposition could be maintained or further translated into different morphologies. When the phase separation path was entered into B2 region, the bicontinuous structure could be maintained. However, when the phase separation path was entered into B1 or B3 region, the bicontinuous structure would be further translated into different morphologies. If the polymer concentration was lower than the composition of critical point, the original bicontinuous structure would be broken to nodule particle due to capillarity effect. However, as the polymer concentration was higher than the composition of critical point, the original bicontinuous structure led to matrix/disperses domain morphology by coalescence effect.

In this study, it can be found that the bicontinuous structure was obtained near the top surface of PMMA membrane when the PMMA/1,4-dioxane casting film was contacted with $n$-propanol only $2 \mathrm{~s}$. As a result of bicontinuous structures, we suppose that the composition path at the top of PMMA casting film might be entered into the unstable region to cause spinodal decomposition.
However, the morphology of PMMA membrane would be further evolved before solidification, at the top would be broken up to form nodule particle due to the capillarity effect, and at the sub-layer led to a matrix/disperse domain morphology by coalescence effect.

\section{Conclusion}

The formation and evolution of bicontinuous structure of PMMA membrane were investigated in this study by freeze-drying the PMMA/1,4 dioxane casting films which were immersed into the alcohol baths for specific durations. The analysis of FTIRmicroscopy and SEM show that the PMMA polymer concentration in the top layer of nascent membrane decreased when the casting film was immersed into $n$-propanol bath. The weak non-solvent (n-propanol) was beneficial to lower the polymer concentration at the interface of casting film and non-solvent. The bicontinuous structure could be formed in the $n$-propanol bath resulted from the composition of dilute PMMA polymer solution in the top layer was entered into the unstable region. It was also found that as increasing the immersed time in $n$-propanol bath, the bicontinuous structure would be broken up to nodules structure due to capillarity effect or led to a matrix/disperse domain morphology by coalescence effect.

\section{Acknowledgements}

The authors wish to sincerely thank the Ministry of Economic Affairs and the National Science Council of Taiwan, ROC, for financially supporting this work.

\section{References}

[1] R.E. Kesting, Synthetic Polymeric Membranes, Wiley, New York, 1985.

[2] M. Mulder, Basic Principles of Membrane Technology, Second edition, Kluwer Academic Publishers, London, 1996

[3] R.C. Ruaan, T. Chang, D.M. Wang, Selection criteria for solvent and coagulation medium in view of macrovoid formation in the wet phase inversion process, J. Polym. Sci. B: Polym. Phys. 37 (1999) 1495.

[4] S.C. Pesek, W.J. Koros, Aqueous quenched asymmetric polysulfone membranes prepared by dry/wet phase separation, J. Membr. Sci. 81 (1993) 71.

[5] D.J. Hellman, A.R. Greenberg, W.B. Krantz, A novel process for membrane fabrication: thermally assisted evaporative phase separation (TAEPS), J. Membr. Sci. 230 (2004) 99.

[6] M.G. Buonomenna, P. Macchi, M. Davoli, E. Drioli, Poly(vinylidene fluoride) membranes by phase inversion: the role the casting and coagulation conditions play in their morphology, crystalline structure and properties, Eur. Polym. J. 43 (2007) 1557.

[7] J.F. Blanco, J. Sublet, Q.T. Nguyen, P. Schaetzel, Formation and morphology studies of different polysulfones-based membranes made by wet phase inversion process, J. Membr. Sci. 283 (2006) 27.

[8] D.M. Wang, F.C. Lin, T.T. Wu, J.Y. Lai, Formation mechanism of the macrovoids induced by surfactant additives, J. Membr. Sci. 142 (1998) 191.

[9] F.C. Lin, D.M. Wang, C.L. Lai, J.Y. Lai, Effect of surfactants on the structure of PMMA membranes, J. Membr. Sci. 123 (1997) 281.

[10] L.P. Cheng, H.Y. Shaw, Phase behavior of a water/2-propanol/poly(methyl methacrylate) cosolvent system, J. Polym. Sci. B: Polym. Phys. 38 (2000) 747.

[11] S.C. Fan, Y.C. Wang, C.L. Li, K.R. Lee, D.J. Liaw, H.P. Huang, J.Y. Lai, Effect of coagulation media on membrane formation and vapor permeation performance of novel aromatic polyamide membrane, J. Membr. Sci. 204 (2002) 67.

[12] S.G. Li, G.H. Koops, M.H.V. Mulder, T. van den Boomgaard, C.A. Smolders, Wet spinning of integrally skinned hollow fiber membranes by a modified dual-bath coagulation method using a triple orifice spinneret, J. Membr. Sci. 94(1994) 329.

[13] H.A. Tsai, C.Y. Kuo, J.H. Lin, D.M. Wang, A. Deratani, C. Pochat-Bohatier, K.R. Lee, J.Y. Lai, Morphology control of polysulfone hollow fiber membranes via water vapor induced phase separation, J. Membr. Sci. 278 (2006) 390.

[14] L.W. Chen, T.H. Young, Effect of nonsolvents on the mechanism of wet-casting membrane formation from EVAL copolymers, J. Membr. Sci. 59 (1991) 15.

[15] H. Matsuyama, K. Nakagawa, T. Maki, M. Teramoto, Studies on phase separation rate in porous polyimide membrane formation by immersion precipitation, J. Appl. Polym. Sci. 90 (2003) 292

[16] A.J. Reuvers, J.W.A. van den Berg, C.A. Smolders, Formation of membranes by means of immersion precipitation. Part I. A model to describe mass transfer during immersion precipitation, J. Membr. Sci. 34 (1987) 45

[17] P. Radovanovic, S.W. Thiel, S.T. Hwang, Formation of asymmetric polysulfone membranes by immersion precipitation. Part I. Modelling mass transport during gelation, J. Membr. Sci. 65 (1992) 213. 
[18] G.R. Fernandes, J.C. Pinto, R. Nobrega, Modelling and simulation of the phaseinversion process during membrane preparation, J. Appl. Polym. Sci. 82 (2001) 3036.

[19] Y.D. Kim, J.Y. Kim, H.K. Lee, S.C. Kim, A new modeling of asymmetric membrane formation in rapid mass transfer system, J. Membr. Sci. 190 (2001) 69.

[20] L.P. Cheng, T.H. Young, W.Y. Chuang, L.Y. Chen, L.W. Chen, The formation mechanism of membranes prepared from the nonsolvent-solvent-crystalline polymer systems, Polymer 42 (2001) 443.

[21] T.H. Young, L.P. Cheng, D.J. Lin, L. Fane, W.Y. Chuang, Mechanisms of PVDF membrane formation by immersion-precipitation in soft (1-octanol) and harsh (water) nonsolvents, Polymer 40 (1999) 5315.

[22] T.H. Young, C.C. Hsieh, L.Y. Chen, Y.S. Huang, Formation mechanism of membranes prepared from the crystalline EVAL polymer-water (nonsolvent)2-propanol (nonsolvent) system, J. Membr. Sci. 159 (1999) 21.

[23] H.A. Tsai, D.H. Huang, S.C. Fan, Y.C. Wang, C.L. Li, K.R. Lee, J.Y. Lai, Investigation of surfactant addition effect on the vapor permeation of aqueous ethanol mixtures through polysulfone hollow fiber membranes, J. Membr. Sci. 198 (2002) 245.

[24] L.P. Cheng, D.J. Lin, C.H. Shih, A.H. Dwan, C.C. Gryte, PVDF membrane formation by diffusion-induced phase separation-morphology prediction based on phase behavior and mass transfer modeling, J. Polym. Sci. B: Polym. Phys. 37 (1999) 2079.
[25] R.A. Zoppi, S. Contant, E.A.R. Duek, F.R. Marques, M.L.F. Wada, S.P. Nunes, Porous poly(L-lactide) films obtained by immersion precipitation process: morphology, phase separation and culture of VERO cells, Polymer 40 (1999) 3275.

[26] J. Eckelt, S. Loske, M.C. Goncalves, B.A. Wolf, Formation of micro- and nanospheric particles (filter dust) during the preparation of cellulose acetate membranes, J. Membr. Sci. 212 (2003) 69

[27] F.J. Tsai, J.M. Torkelson, Microporous poly(methyl methacrylate) membranes Effect of a low-viscosity solvent on the formation mechanism, Macromolecules 23 (1990) 4983.

[28] H. Tanaka, Viscoelastic phase separation, J. Phys.: Condens. Matter 12 (2000) 207.

[29] J.W. Cahn, Phase separation by spinodal decomposition in isotropic systems, J Chem. Phys. 42 (1965) 93.

[30] E.D. Siggia, Late stages of spinodal decomposition in binary mixtures, Phys. Rev. A 20 (1979) 595.

[31] H. Fujita, Polymer Solutions, Elsevier, Amsterdam, 1990.

[32] F.J. Tsai, J.M. Torkelson, Roles of phase separation mechanism and coarsening in the formation of poly(methyl methacrylate) asymmetric membranes, Macromolecules 23 (1990) 775. 